\title{
Comparison of childhood asthma incidence in 3 neighbouring cities in southwestern Ontario: a 25-year longitudinal cohort study
}

\author{
Dhenuka Radhakrishnan MD, Sarah E. Bota BA, April Price MD, Alexandra Ouédraogo MSc, \\ Murad Husein MD, Kristin K. Clemens MD, Salimah Z. Shariff PhD
}

\section{Abstract}

Background: Air pollution is a known trigger for exacerbations among individuals with asthma, but its role in the development of new-onset asthma is unclear. We compared the rate of new asthma cases in Sarnia, a city with high pollution levels, with the rates in 2 neighbouring regions in southwestern Ontario, Canada.

Methods: Using a population-based birth cohort design and linked health administrative data, we compared the hazard of incident asthma among children 0 to 10 years of age between those born in Lambton (Sarnia) and those born in Windsor and LondonMiddlesex, for the period Apr. 1, 1993, to Mar. 31, 2009. We used Cox proportional hazards models to adjust for year of birth and exposure to air pollutants (nitrogen dioxide, sulphur dioxide $\left[\mathrm{SO}_{2}\right]$, ozone and small particulate matter $\left[\mathrm{PM}_{2.5}\right]$ ), as well as maternal, geographic and socioeconomic factors.

Results: Among 114427 children, the highest incidence of asthma was in Lambton, followed by Windsor and London-Middlesex (30.3, 24.4 and 19.8 per 1000 person-years, respectively; $p<0.001)$. Relative to Lambton, the hazard of asthma, adjusted for socioeconomic and perinatal factors, was lower in Windsor (hazard ratio [HR] 0.72, 95\% confidence interval [Cl] 0.67-0.77) and LondonMiddlesex (HR $0.65,95 \% \mathrm{Cl} 0.61-0.69)$. Inclusion of air pollutants attenuated this relative difference in both Windsor (HR $0.79,95 \%$ Cl 0.62-1.01) and London-Middlesex (HR 0.89, 95\% Cl 0.64-1.24).

Interpretation: We identified a higher incidence of asthma among children born in Lambton (Sarnia) relative to 2 other regions in southwestern Ontario. Higher levels of air pollution (particularly $\mathrm{SO}_{2}$ and $\mathrm{PM}_{2.5}$ ) in this region, as experienced by children in their first year of life, may be contributory.

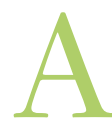

sthma is the most common chronic disease in children, with a Canadian prevalence of $15 \%$ to $25 \% .{ }^{1}$ Asthma exacerbations reduce quality of life and are a leading cause of emergency department visits and hospital admissions. ${ }^{2}$ Whereas numerous risk factors for asthma exacerbations are known, ${ }^{3-12}$ identifying new, modifiable risk factors for onset of this condition could lead to primary prevention.

There is a clear association between asthma exacerbations and air pollution in those with previously diagnosed asthma $^{13-17}$ but less certainty as to whether air pollution might contribute to new-onset asthma. ${ }^{18-21}$ This association has been challenging to study because of inadequate attribution of air pollution exposure, owing to population mobility and difficulties in differentiating between workplace and residential exposures. Furthermore, most research has focused on adults, ${ }^{22,23}$ whereas asthma likely develops during gestation or within the first year of life. ${ }^{24,25}$ As such, it is necessary to elucidate the influence of exposure to pollution on development of asthma in children. A recent systematic review of the relation between incident asthma in children and exposure to air pollution was inconclusive. ${ }^{26}$

In the province of Ontario, Canada, a spatial analysis of asthma prevalence between 2002 and 2006 identified a cluster of high rates among children 10 to 14 years of age in and around the city of Sarnia. ${ }^{27}$ Sarnia, in southwestern Ontario, is home to the "Chemical Valley," which accounts for $40 \%$ of Canada's chemical processing facilities. These facilities produce a wide range of products, such as plastics, industrial materials and a variety of consumer goods..$^{28,29}$ This region has

Competing interests: None declared.

This article has been peer reviewed.

Correspondence to: Dhenuka Radhakrishnan, dradhakrishnan@cheo.on.ca

CMAJ Open 2021. DOI:10.9778/cmajo.20200130 
been recorded as having the worst air quality in the country, ${ }^{30}$ with measurements above the limits recommended by the World Health Organization. ${ }^{31}$ In recent years, this region has received media and government attention because of revelations of unreported toxic emissions and high levels of morbidity as a result of exposure to pollutants. ${ }^{18,32,33}$

We aimed to clarify the link between exposure to air pollution and incident asthma in a subset of Canadian children. Using a population-based birth cohort design, we compared the rate of new asthma cases in Sarnia with rates in 2 neighbouring regions in southwestern Ontario, with adjustment for various factors, including year of birth; maternal, geographic and socioeconomic factors; and exposure to air pollutants. We also examined whether the hazard of incident asthma was attenuated by the reduction in air pollution levels in more recent years.

\section{Methods}

\section{Design and setting}

We conducted a longitudinal birth cohort study spanning 25 years (Apr. 1, 1993, to Mar. 31, 2018) using linked health administrative databases available at ICES. We chose this period because it had good data availability and because it overlaps with an observed change in asthma trends in Ontario. ${ }^{34} \mathrm{We}$ compared the incidence of asthma among children born between Apr. 1, 1993, and Mar. 31, 2009, in 3 neighbouring urban regions in southwestern Ontario. The reporting of this study follows the Reporting of Studies Conducted Using Observational Routinely Collected Health Data (RECORD) guidelines for observational studies. ${ }^{35,36}$

\section{Data sources}

In the province of Ontario (population 14 million), more than $99 \%$ of residents are eligible for government-funded health insurance through the Ontario Health Insurance Plan (OHIP). We used encoded identifiers based on the OHIP number to link individuals to multiple health administrative data sets, including the OHIP data set, which contains information on all physician outpatient visits; the Ontario Registered Persons Database, which provides basic demographic information; and the Canadian Institute for Health Information Discharge Abstract Database (CIHI-DAD), which details all hospital admissions. The MOMBABY data set is derived from the CIHI-DAD and includes records for all mothers linked to their Ontario-born children. The Ontario Marginalization Index ${ }^{37,38}$ is a geographically based marker of socioeconomic status, consisting of 4 dimensions: residential instability, material deprivation, dependency and ethnic concentration. We linked these data sets using the unique encoded identifiers and analyzed them at ICES (Appendix 1, Table S1, available at www.cmajopen.ca/content/9/2/433/suppl/DC1).

For data on air quality, we used Ontario Ministry of Environment air quality data ${ }^{39}$ and Environment Canada's National Air Pollution Surveillance data. ${ }^{40}$ These publicly available data sets provide information about air pollution across the province.

\section{Participants}

We included all live in-hospital births that occurred within the Lambton (where Sarnia is the major urban centre), Windsor and London-Middlesex Local Health Integration Network (LHIN) subregions over a 15-year accrual period (between Apr. 1, 1993, and Mar. 31, 2009). Since 2006, LHINs have been the health authorities responsible for regional administration of health care services in Ontario. ${ }^{41}$

We selected these 3 subregions for comparison because they align with previously conducted studies; ${ }^{42,43}$ because they are geographically proximate, with each of their major cities (Sarnia, Windsor and London, respectively) separated by no more than $200 \mathrm{~km}$; and because they have similar climate, outdoor allergens, ethnic diversity, and lifestyle and socioeconomic exposures. These centres also have integration of many pediatric health services and are served by a single pediatric tertiary care hospital. The subregions differ in terms of their air pollution levels because of the major industries present in each (Appendix 1, Supplementary Methods).

We excluded births that occurred outside these subregions and those for which the mother lived in a different subregion in the 1-year period before delivery (to establish perinatal exposure). We excluded deliveries of multiple births and births before 37 weeks gestation, because these situations are known risk factors for asthma. ${ }^{44} \mathrm{We}$ further excluded deliveries in which the mother was younger than 14 years or older than 50 years and those involving infants who died or did not reside in the region of birth for at least 1 year (to establish early-life exposure).

\section{Exposures}

Our primary exposure of interest was the geographic area of birth, namely, the LHIN subregions of Lambton, Windsor and London-Middlesex. We determined the area of birth from the child's postal code at birth (Appendix 1, Table S2).

We also considered the following secondary exposures: the fiscal year in which the child was born, to corroborate air pollution levels in utero and during the first year of life (the critical period of susceptibility), and the ambient concentration of various air pollutants, as a proxy for exposure to air pollution. The most common air pollutants, found as gases or particles in the atmosphere we breathe, are produced from industrial processes or as the by-products of biomass or fuel combustion (e.g., motor vehicle exhaust in traffic-related air pollution). We considered the following pollutants: nitrogen dioxide $\left(\mathrm{NO}_{2}\right)$, ground-level ozone $\left(\mathrm{O}_{3}\right)$, sulphur dioxide $\left(\mathrm{SO}_{2}\right)$ and particulate matter $2.5 \mu \mathrm{m}$ or smaller $\left(\mathrm{PM}_{2.5}\right)$. The 2020 Canadian ambient air quality standards (www.ccme.ca/ en/air-quality-report\#slide-7) recommend the following levels for these pollutants: $\mathrm{NO}_{2}$ less than 17.0 parts per billion (ppb)/year, $\mathrm{O}_{3}$ less than $62 \mathrm{ppb} / 8$ hours, $\mathrm{SO}_{2}$ less than $5.0 \mathrm{ppb} /$ year and $\mathrm{PM}_{2.5}$ less than $8.8 \mu \mathrm{g} / \mathrm{m}^{3} /$ year.

We assigned exposure to each air pollutant for each child on the basis of forward sortation area or city region of birth and fiscal year of birth. We also included additional covariables reported to be associated with risk of childhood asthma (Appendix 1, Supplementary Methods). 


\section{Outcomes}

Our primary outcome was the incidence of physiciandiagnosed asthma, as identified using the Ontario Asthma Surveillance Information System. This system has sensitivity of $89 \%$ and specificity of $72 \%$ for detecting asthma in children, based on an algorithm that includes 1 hospital admission or 2 physician outpatient visits for asthma within 2 years. ${ }^{45} \mathrm{It}$ has been widely used to evaluate asthma rates and related health care burden in Ontario. ${ }^{1,4,45-48}$

We followed each child for a maximum of 10 years, which a previous study indicated would allow capture of up to $85 \%$ of childhood asthma cases. ${ }^{49}$ Our secondary outcome was persistent asthma beyond age 6 years (Appendix 1, Supplementary Methods).

\section{Statistical analysis}

We compared baseline cohort characteristics between regions using 1-way analysis of variance and $\chi^{2}$ tests as appropriate. We constructed Kaplan-Meier curves to examine the 10-year incidence of asthma and compared regions using the log-rank test. We censored individuals at the age of 10 years or at death.

We used adjusted Cox proportional hazards models to assess the relative difference in hazard of asthma by age 10 in the 3 subregions, with Lambton as the reference category. We adjusted the models for maternal age, maternal asthma, sex, rural geography, neighbourhood material deprivation, neighbourhood ethnic concentration, cesarean delivery and fiscal year of birth. Because of recent declines in pollution levels, we tested for an interaction between subregion and year of birth using the likelihood ratio test and, if the result was significant, reported results in 4-year groupings (fiscal years 1993-1996, 1997-2000, 2001-2004 and 2005-2008). We also checked for differences in the hazard of asthma stratified by age 0 to less than 2 years, 2 to less than 6 years, and 6 years or older, corresponding to early and late preschool and older childhood age groups, respectively. For our secondary outcome, we developed a second adjusted Cox proportional hazards model to examine the hazard of persistent asthma beyond age 6 years.

To compare the hazard of incident asthma attributable to $\mathrm{NO}_{2}, \mathrm{O}_{3}, \mathrm{SO}_{2}$ or $\mathrm{PM}_{2.5}$, we developed 4 predefined sensitivity models as described above, but each with the additional inclusion of exposure to 1 pollutant. We restricted these analyses to include only patients with complete information for all pollutant exposures. We developed models with and without cubic splines to account for any nonlinear relations between pollutant exposures and asthma incidence. In a final analysis, we included all pollutants in the same model.

We express the results as hazard ratios (HRs) and 95\% confidence intervals (CIs). We conducted all analyses with SAS software, version 9.4 (SAS Institute), and we interpreted 2 -tailed $p$ values less than 0.05 as statistically significant.

\section{Ethics approval}

This study was approved by the Children's Hospital of Eastern Ontario research ethics board (CHEO REB No. 21/03PE).

\section{Results}

We identified 2112270 children who were born in an Ontario hospital between the fiscal years of 1993 and 2008. After exclusions for data integrity and birth outside the regions of interest, we retained a total of 114427 children for the analysis (Figure 1): 16758 (14.6\%) born in Lambton, 34962 (30.6\%) born in Windsor and 62707 (54.8\%) born in London-Middlesex.

The most notable differences in baseline population characteristics (Table 1) were rurality, which was highest in Lambton (27.2\% of the population), and neighbourhoodlevel characteristics, such as income quintile distribution, with evidence of lower socioeconomic status in Windsor, along with higher levels of ethnic concentration and material deprivation.

Average air pollutant levels at birth differed between regions, with the highest concentration of $\mathrm{NO}_{2}$ in Windsor (34.9 [standard deviation, SD 3.9] ppb) and the highest concentrations of $\mathrm{O}_{3}$ (41.8 [SD 1.9] ppb), $\mathrm{PM}_{2.5}$ (23.6 [SD $2.8] \mathrm{ppb})$ and $\mathrm{SO}_{2}(8.8$ [SD 1.8] ppb) in Lambton. Air pollutant levels generally decreased over the study period, although levels of $\mathrm{O}_{3}$ remained stable (Appendix 1, Figure S1, Panels A-D).

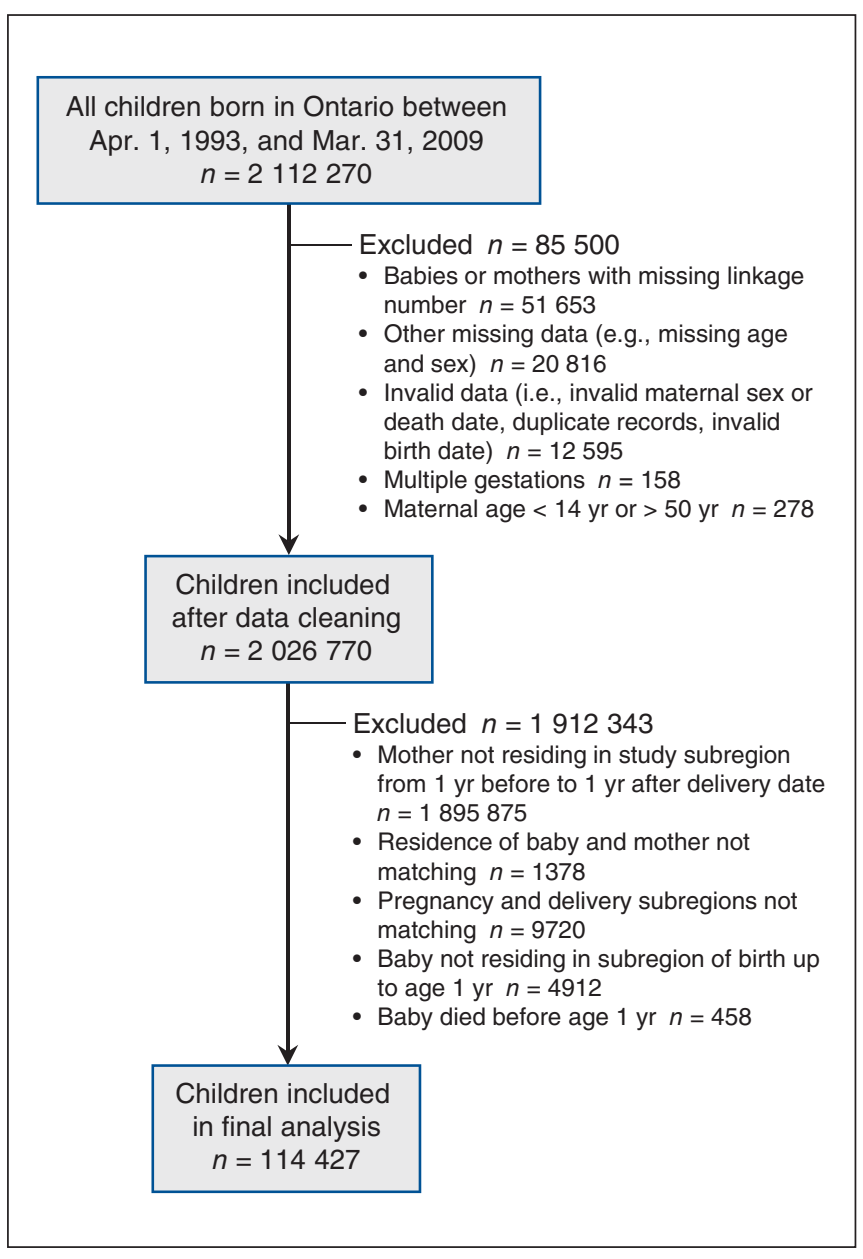

Figure 1: Flow chart for cohort. 


\begin{tabular}{|c|c|c|c|c|}
\hline \multirow[b]{2}{*}{ Characteristic } & \multicolumn{3}{|c|}{ LHIN subregion; no. (\%) of patients* } & \multirow[b]{2}{*}{$p$ value } \\
\hline & $\begin{array}{l}\text { Lambton } \\
n=16758\end{array}$ & $\begin{array}{l}\text { Windsor } \\
n=34962\end{array}$ & $\begin{array}{l}\text { London-Middlesex } \\
\qquad n=62707\end{array}$ & \\
\hline \multicolumn{5}{|l|}{$\begin{array}{l}\text { Maternal characteristics at } \\
\text { delivery date }\end{array}$} \\
\hline Age, yr, mean \pm SD & $27.94 \pm 5.37$ & $28.30 \pm 5.47$ & $29.11 \pm 5.44$ & $<0.001$ \\
\hline \multicolumn{5}{|l|}{ Age group, yr } \\
\hline $15-29$ & $10203(60.9)$ & $20261(58.0)$ & $31930(50.9)$ & \multirow[t]{3}{*}{$<0.001$} \\
\hline 30-39 & $6285(37.5)$ & $14029(40.1)$ & $29366(46.8)$ & \\
\hline $40-49$ & $270(1.6)$ & $672(1.9)$ & $1411(2.3)$ & \\
\hline Rural geography & 4557 (27.2) & $15(0.0)$ & $3264(5.2)$ & $<0.001$ \\
\hline \multicolumn{5}{|l|}{ Income quintile } \\
\hline 1 (lowest) & $3918(23.4)$ & $10971(31.4)$ & $14272(22.8)$ & \multirow[t]{6}{*}{$<0.001$} \\
\hline 2 & $3408(20.3)$ & $9105(26.0)$ & 13397 (21.4) & \\
\hline 3 & $3394(20.3)$ & $7551(21.6)$ & $12723(20.3)$ & \\
\hline 4 & $3406(20.3)$ & $4083(11.7)$ & $12277(19.6)$ & \\
\hline 5 (highest) & $2509(15.0)$ & $3200(9.2)$ & $9887(15.8)$ & \\
\hline Missing & $123(0.7)$ & $52(0.1)$ & $151(0.2)$ & \\
\hline \multicolumn{5}{|l|}{ Residential instability } \\
\hline 1 (least instability) & $2391(14.3)$ & $2810(8.0)$ & $9436(15.0)$ & \multirow[t]{5}{*}{$<0.001$} \\
\hline 2 & $3483(20.8)$ & $4783(13.7)$ & $11554(18.4)$ & \\
\hline 3 & $4533(27.0)$ & $6985(20.0)$ & 11834 (18.9) & \\
\hline 4 & $3681(22.0)$ & $11184(32.0)$ & $13382(21.3)$ & \\
\hline 5 (most instability) & 2670 (15.9) & $9200(26.3)$ & $16501(26.3)$ & \\
\hline \multicolumn{5}{|l|}{ Material deprivation } \\
\hline 1 (least deprived) & $2541(15.2)$ & $3993(11.4)$ & $11889(19.0)$ & \multirow[t]{5}{*}{$<0.001$} \\
\hline 2 & $3319(19.8)$ & $6411(18.3)$ & $10960(17.5)$ & \\
\hline 3 & $3400(20.3)$ & $5455(15.6)$ & $13039(20.8)$ & \\
\hline 4 & $3114(18.6)$ & $6975(20.0)$ & $13119(20.9)$ & \\
\hline 5 (most deprived) & $4384(26.2)$ & $12128(34.7)$ & $13700(21.8)$ & \\
\hline \multicolumn{5}{|l|}{ Dependency } \\
\hline 1 (lowest & $1543(9.2)$ & $5591(16.0)$ & $15393(24.5)$ & \multirow[t]{5}{*}{$<0.001$} \\
\hline 2 & $2934(17.5)$ & 7869 (22.5) & $16275(26.0)$ & \\
\hline 3 & 3575 (21.3) & $7872(22.5)$ & $14897(23.8)$ & \\
\hline 4 & $4277(25.5)$ & $8810(25.2)$ & $9438(15.1)$ & \\
\hline 5 (highest & $4429(26.4)$ & $4820(13.8)$ & $6704(10.7)$ & \\
\hline \multicolumn{5}{|l|}{ Ethnic concentration } \\
\hline 1 (lowest) & $6903(41.2)$ & $3509(10.0)$ & $9437(15.0)$ & \multirow[t]{5}{*}{$<0.001$} \\
\hline 2 & $4688(28.0)$ & $4400(12.6)$ & $11755(18.7)$ & \\
\hline 3 & $3435(20.5)$ & $6268(17.9)$ & $17248(27.5)$ & \\
\hline 4 & $1553(9.3)$ & $10080(28.8)$ & $15731(25.1)$ & \\
\hline 5 (highest) & $179(1.1)$ & $10705(30.6)$ & $8536(13.6)$ & \\
\hline \multicolumn{5}{|l|}{ Newborn characteristics } \\
\hline Sex, female & $8224(49.1)$ & $16982(48.6)$ & $30543(48.7)$ & 0.6 \\
\hline Low birth weight or preterm† & $1445(8.6)$ & $3104(8.9)$ & $5533(8.8)$ & 0.6 \\
\hline
\end{tabular}




\begin{tabular}{|c|c|c|c|c|}
\hline \multirow[b]{2}{*}{ Characteristic } & \multicolumn{3}{|c|}{ LHIN subregion; no. (\%) of patients* } & \multirow[b]{2}{*}{$p$ value } \\
\hline & $\begin{array}{l}\text { Lambton } \\
n=16758\end{array}$ & $\begin{array}{c}\text { Windsor } \\
n=34962\end{array}$ & $\begin{array}{l}\text { London-Middlesex } \\
\qquad n=62707\end{array}$ & \\
\hline \multicolumn{5}{|c|}{ Pollutant exposures in year of birth } \\
\hline $\mathrm{NO}_{2}, \neq \mathrm{ppb}$, mean $\pm \mathrm{SD}$ & $28.4 \pm 4.8$ & $34.9 \pm 3.9$ & $28.5 \pm 4.2$ & $<0.001$ \\
\hline $\mathrm{O}_{3}, \ddagger \mathrm{ppb}$, mean $\pm \mathrm{SD}$ & $41.8 \pm 1.9$ & $39.6 \pm 2.6$ & $40.3 \pm 2.0$ & $<0.001$ \\
\hline $\mathrm{PM}_{2.5}, \neq \mathrm{ppb}$, mean $\pm \mathrm{SD}$ & $23.6 \pm 2.8$ & $21.3 \pm 1.5$ & $17.7 \pm 1.6$ & $<0.001$ \\
\hline $\mathrm{SO}_{2}, \ddagger \mathrm{ppb}$, mean $\pm \mathrm{SD}$ & $8.8 \pm 1.8$ & $6.6 \pm 1.7$ & $2.75 \pm 0.9$ & $<0.001$ \\
\hline \multicolumn{5}{|c|}{ 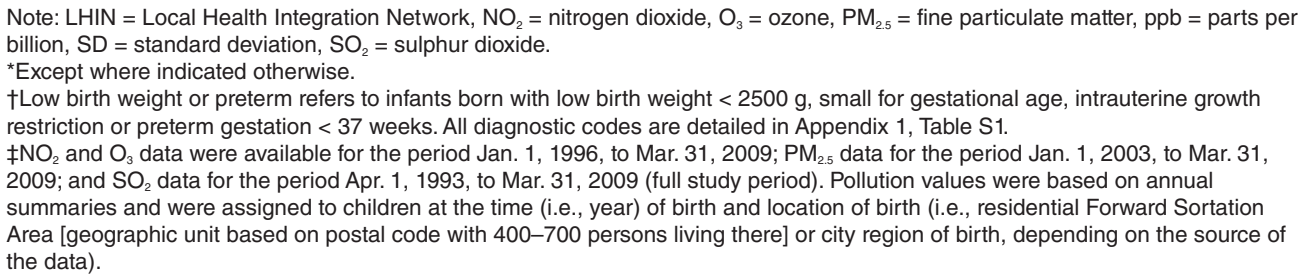 } \\
\hline
\end{tabular}

\section{Asthma incidence}

The overall cumulative incidence of asthma by age 10 years was 22.6 per 1000 person-years, with the highest incidence in Lambton, intermediate incidence in Windsor and the lowest incidence in London-Middlesex (30.3, 24.4 and 19.8 per 1000 person-years, respectively; $p<0.001$ ) (Figure 2).

We found a significant interaction by birth year $(p<0.001)$. When we stratified models by fiscal year eras, the unadjusted and adjusted HRs remained significant across the years, with estimates attenuating over time (Table 2). The lowest hazard of asthma persisted in London-Middlesex (for birth years 2005-2008, adjusted HR 0.65, 95\% CI 0.60-0.71), followed by Windsor (for birth years 2005-2008, adjusted HR 0.67, $95 \%$ CI $0.61-0.74)$, relative to Lambton. When we stratified the models by age categories, we found that the excess hazard of asthma in Lambton was most pronounced at younger ages, between 0 and 2 years (Appendix 1, Table S3).

In our secondary analysis, we found that the adjusted hazard of persistent asthma beyond age 6 was still lowest in London-Middlesex (HR 0.62, 95\% CI 0.59-0.65), followed by Windsor (HR 0.76, 95\% CI 0.72-0.80), relative to Lambton (Appendix 1, Table S4).

\section{Sensitivity analyses}

In sensitivity analyses with a restricted sample size $(n=$ 44737 , for births between fiscal years 2003 and 2008), including only those children with complete information for all pollutant exposures, the hierarchy of the adjusted hazard of asthma between subregions was preserved, although the magnitude of the difference was reduced with the sequential addition of individual air pollutants, the greatest reduction being noted after the addition of $\mathrm{SO}_{2}$. When all 4 air pollutants were combined, the difference in adjusted hazard of asthma was further reduced and no longer significantly different between regions (Table 3). Using cubic splines to represent a potential nonlinear association between air pollutants and hazard of asthma did not further change these results (Appendix 1, Table S5, Figure S2).

\section{Interpretation}

In this population-based study comparing 3 cities in southwestern Ontario that had varied levels of air pollution over 25 years, we observed a significantly lower cumulative incidence of asthma in London-Middlesex and Windsor compared with Lambton (Sarnia). This difference was present after adjustment for multiple confounders associated with asthma risk, such as sex, socioeconomic factors and urban versus rural setting. Although the hazard of incident asthma declined in more recent years, the hierarchy of adjusted asthma risk between subregions was preserved and remained significant. These findings were most apparent in children 0 to 2 years of age, but also remained robust when we examined for persistent asthma beyond the age of 6 years. The difference in asthma risk estimates was reduced with further adjustment for exposure to $\mathrm{SO}_{2}$ and $\mathrm{PM}_{2.5}$ and was no longer significant in a subset of children when all 4 air pollutants were included in the model.

Our results suggest that children in Sarnia have an increased risk of developing asthma, which might be due to higher levels of air pollutants in this region. For our sample of more than 100000 children born in southwestern Ontario over a 16-year period, higher levels of $\mathrm{PM}_{2.5}$ and $\mathrm{SO}_{2}$ were present in the first year of life for children born and living in the Lambton LHIN subregion (which includes Sarnia). We also found that the decline in the risk of asthma in more recent years paralleled the concurrent decrease in air pollution observed following the closure of certain chemical and polymer industries and coal plants. ${ }^{50}$

Our results are similar to those of the few other studies that have explored and identified a relation between incidence of asthma and exposure to air pollution in children. ${ }^{15,16}$ However, because of its natural experimental design, our study strengthens 


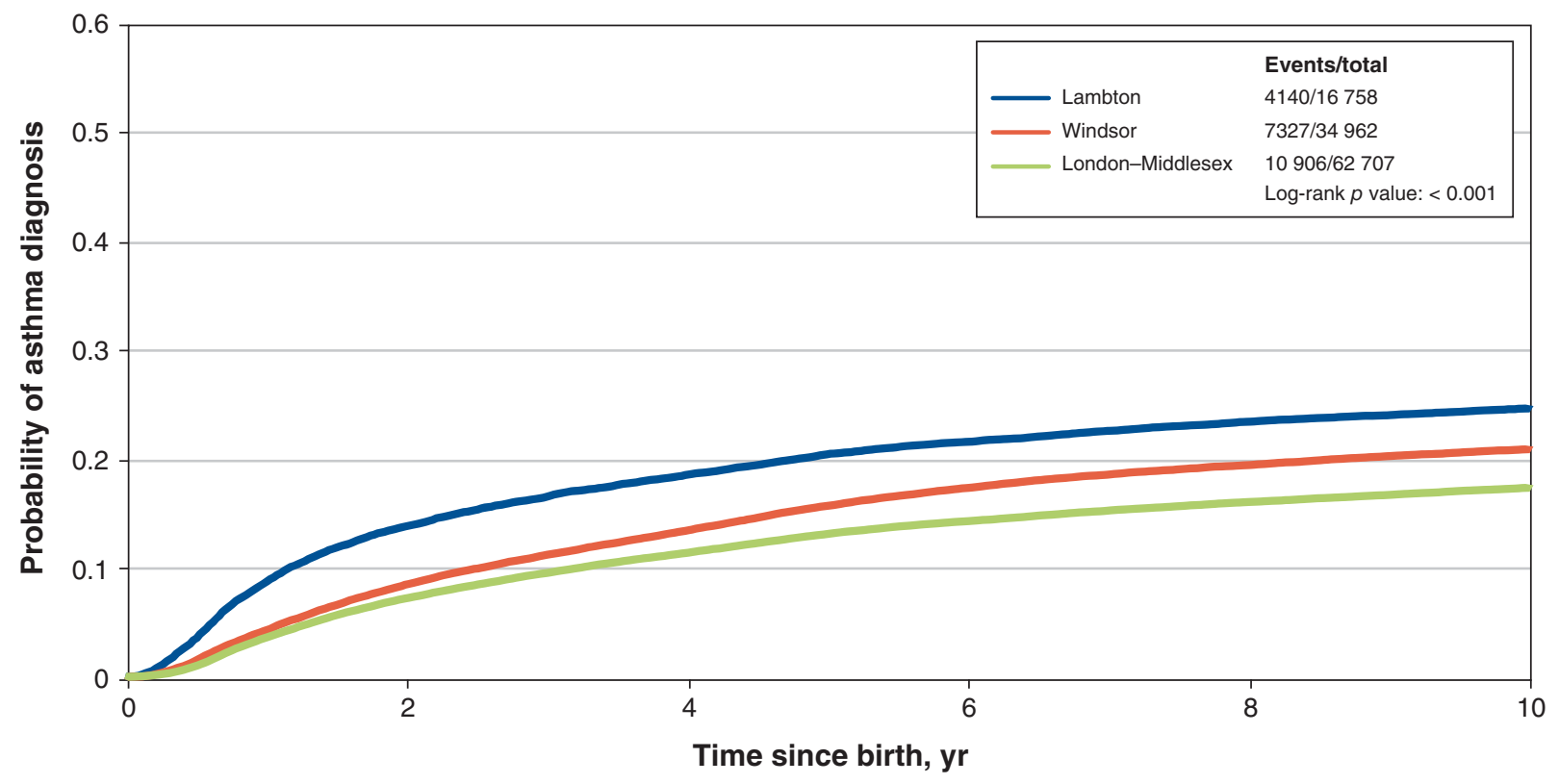

Figure 2: Probability of developing asthma by region of birth, censored at age 10 years.

these previous observations by showing an increased risk of asthma relative to regions with lower air pollution levels. A recent study of children in California showed reductions in asthma incidence concurrent with a reduction in air pollution, ${ }^{51}$ suggesting a possible dose-response effect. That previous study relied on reporting by the patient or parent of an asthma diagnosis (which may be unreliable), whereas we used physician diagnosis of asthma as the outcome (a more valid approach) and similarly showed reductions in asthma incidence with decline in ambient air pollution levels in recent years.

Reduced air pollution may not be the only reason for recent decreases in the incidence of asthma. Lower rates of public smoking and increases in protective factors such as breastfeeding may have also contributed. In our analyses that adjusted for all 4 air pollutant exposures in combination, the hazard ratios did not approximate 1 , which suggests there may have been residual confounding not fully addressed by our methods to attribute air pollutant exposures or other unmeasured environmental exposures. However, in this adjusted analysis, the difference in the hazard of asthma between regions, particularly for the comparison between London-Middlesex and Lambton, was no longer statistically different, lending further support to the likelihood of air pollution being an important mechanism in the development of childhood asthma.

Recent literature has focused on the effect of traffic-related air pollution on asthma development, ${ }^{52-55}$ because the measured effects of industry-related pollutants have been inconsistent in previous studies, perhaps due to inaccuracies in assignment of pollution exposure. ${ }^{56-58}$ In our study, we were able to analyze the difference in asthma risk between regions attributable to each type of air pollutant sequentially and found that adjustment for exposure to $\mathrm{NO}_{2}$ and $\mathrm{O}_{3}$ (compounds that are present in the atmosphere primarily because of traffic-related air pollution) did not really change the hazard of incident asthma. Adjustment for $\mathrm{SO}_{2}$ and $\mathrm{PM}_{2.5}$ significantly attenuated the difference in asthma risk between London-Middlesex or Windsor and Lambton, suggesting that these may be the most contributory air pollutants to explain differences in asthma risk in this region. Although $\mathrm{PM}_{2.5}$ and $\mathrm{SO}_{2}$ are present in traffic-related air pollution, the largest sources in Sarnia are from major industrial processes, including petrochemical processing and smelting.

A few recent studies have linked $\mathrm{PM}_{2.5}$ to new-onset asthma both in the United States and globally. ${ }^{51,59-61}$ In Canada, Buteau and colleagues ${ }^{19}$ examined the incidence of asthma in relation to proximity to industrial air pollution emitters in a population-based birth cohort and found that the hazard of asthma incidence was proportional to increasing exposure to $\mathrm{PM}_{2.5}$ and $\mathrm{SO}_{2}$. In their cohort study, Clark and colleagues ${ }^{18}$ similarly showed that the incidence of asthma in preschool children was proportional to the distance from industrial emitters, within a $10-\mathrm{km}$ radius of the child's residence at birth and during the first year of life. Our current study supports these previous studies, although the latter had limited duration of follow-up and lack of adjustment for trafficrelated air pollutants. The mechanisms for how air pollution might increase a child's susceptibility to development of asthma are unclear, but they may be secondary to epigenetic pathways or damage to airway epithelium due to oxidative 


\begin{tabular}{|c|c|c|c|}
\hline \multirow{2}{*}{$\begin{array}{l}\text { Birth (fiscal) year and } \\
\text { LHIN subregion }\end{array}$} & \multicolumn{3}{|c|}{$\mathrm{HR}(95 \% \mathrm{Cl})$} \\
\hline & Unadjusted & Adjusted* & Adjusted $†$ \\
\hline \multicolumn{4}{|l|}{$1993-1996$} \\
\hline Lambton & 1.00 (Ref.) & 1.00 (Ref.) & NA \\
\hline Windsor & $0.68(0.64-0.73)$ & $0.60(0.56-0.65)$ & \\
\hline London-Middlesex & $0.57(0.54-0.61)$ & $0.54(0.51-0.58)$ & \\
\hline \multicolumn{4}{|l|}{$1997-2000$} \\
\hline Lambton & 1.00 (Ref.) & 1.00 (Ref.) & \\
\hline Windsor & $0.84(0.77-0.90)$ & $0.77(0.71-0.84)$ & NA \\
\hline London-Middlesex & $0.63(0.59-0.68)$ & $0.61(0.56-0.66)$ & \\
\hline \multicolumn{4}{|l|}{ 2001-2004 } \\
\hline Lambton & 1.00 (Ref.) & 1.00 (Ref.) & 1.00 (Ref.) \\
\hline Windsor & $0.90(0.83-0.97)$ & $0.80(0.73-0.88)$ & $0.81(0.72-0.91)$ \\
\hline London-Middlesex & $0.69(0.64-0.75)$ & $0.65(0.60-0.71)$ & $\begin{array}{c}0.65(0.58-0.72) \\
\text { (Jan. 1, 2003-Mar 31, 2005; } \\
n=15558)\end{array}$ \\
\hline \multicolumn{4}{|l|}{ 2005-2008 } \\
\hline Lambton & 1.00 (Ref.) & 1.00 (Ref.) & 1.00 (Ref.) \\
\hline Windsor & $0.85(0.78-0.92)$ & $0.67(0.61-0.74)$ & $0.67(0.61-0.74)$ \\
\hline London-Middlesex & $0.77(0.71-0.83)$ & $0.65(0.60-0.71)$ & $\begin{array}{c}0.65(0.60-0.71) \\
(n=29179)\end{array}$ \\
\hline \multicolumn{4}{|l|}{ 1993-2008 (all years) } \\
\hline Lambton & 1.00 (Ref.) & 1.00 (Ref.) & 1.00 (Ref.) \\
\hline Windsor & $0.81(0.78-0.84)$ & $0.70(0.67-0.73)$ & $0.72(0.67-0.77)$ \\
\hline London-Middlesex & $0.66(0.63-0.68)$ & $\begin{array}{c}0.61(0.58-0.63) \\
(n=114427)\end{array}$ & $\begin{array}{c}0.65(0.61-0.69) \\
(n=44737)\end{array}$ \\
\hline \multicolumn{4}{|c|}{$\begin{array}{l}\text { Note: } \mathrm{Cl}=\text { confidence interval, } \mathrm{HR} \text { = hazard ratio, LHIN = Local Health Integration Network, NA = not available, Ref. = reference } \\
\text { category. } \\
\text { `Adjusted for maternal age, maternal asthma, sex, rural geography, neighbourhood material deprivation, neighbourhood ethnic } \\
\text { concentration, cesarean delivery and fiscal year. The number of individuals per model is variable because the cohorts were } \\
\text { restricted to children with no missing data for exposures to pollutants. } \\
\text { †Adjusted for all variables listed above and restricted to children with data available for exposures to all pollutants. }\end{array}$} \\
\hline
\end{tabular}

stress, which may result in airway remodelling, inflammatory and immunologic responses, and enhanced respiratory sensitization to aeroallergens. ${ }^{62,63}$

\section{Limitations}

This study had several strengths, including a populationbased design, a long observation period and a large sample size, all of which contribute to the generalizability of the findings. One of the potential limitations is that the study design did not allow for individual measures of air pollution exposure, which could vary according to differences in time spent outdoors or type of dwelling and indoor ventilation. Some of this potential misclassification would have been addressed by our natural study design, which allowed comparison of asthma incidence in a subregion that had very high ambient pollution with otherwise comparable geographic regions having substantially lower overall pollution levels, such that small variations in individuals' exposure within a given subregion might not have been important.

Our assignment of air pollution exposure at birth and in the first year of life did not account for potential movement of children between the 3 study subregions later in life, which could have diluted the observed relation between air pollution and asthma incidence. Similarly, we did not account for changes in marginalization characteristics over the life of the child. However, the premise of this study was to explore the impact of exposures early in life (in utero and up to 1 year of age) on asthma incidence, given growing evidence that this critical window is most deterministic in an individual's lifetime asthma risk. ${ }^{25,64}$

Findings in the literature support the proposition that early-life exposures influence development of the lungs ${ }^{65}$ as well as the gut microbiome and immune system, ${ }^{66,67}$ such that exposures later in life (e.g., caused by moving to regions with 
Table 3: Association of individual air pollution exposures with adjusted Cox proportional hazards estimates for development of asthma by age 10 years

\begin{tabular}{|c|c|c|}
\hline \multirow[b]{2}{*}{ Model and LHIN subregion } & \multicolumn{2}{|c|}{ Hazard ratio $(95 \% \mathrm{Cl})$} \\
\hline & Adjusted $^{*}$ & $\begin{array}{c}\text { Adjusted } \dagger \\
\text { (Jan. 1, 2003-Mar. 31, 2009) } \\
n=44737\end{array}$ \\
\hline \multicolumn{3}{|l|}{ Model with no pollutants } \\
\hline Lambton & 1.00 (Ref.) & 1.00 (Ref.) \\
\hline Windsor & $0.7(0.67-0.73)$ & $0.72(0.67-0.77)$ \\
\hline London-Middlesex & $\begin{array}{c}0.61(0.58-0.63) \\
\text { (Apr. 1, 1993-Mar. 31, 2009; } \\
\quad n=114427)\end{array}$ & $0.65(0.61-0.69)$ \\
\hline \multicolumn{3}{|l|}{ Model A: $\mathrm{NO}_{2}$} \\
\hline Lambton & 1.00 (Ref.) & 1.00 (Ref.) \\
\hline Windsor & $0.72(0.67-0.77)$ & $0.70(0.62-0.81)$ \\
\hline London-Middlesex & $\begin{array}{c}0.63(0.60-0.66) \\
(\operatorname{Jan} 1,1996-M a r 31,2009 \\
n=92809)\end{array}$ & $0.65(0.60-0.69)$ \\
\hline \multicolumn{3}{|l|}{ Model B: $\mathrm{O}_{3}$} \\
\hline Lambton & 1.00 (Ref.) & 1.00 (Ref.) \\
\hline Windsor & $0.73(0.69-0.77)$ & $0.72(0.67-0.78)$ \\
\hline London-Middlesex & $\begin{array}{c}0.62(0.59-0.65) \\
\text { (Jan. 1, 1996-Mar. 31, 2009; } \\
n=92 \text { 809) }\end{array}$ & $0.65(0.60-0.69)$ \\
\hline \multicolumn{3}{|l|}{ Model C: $\mathrm{SO}_{2}$} \\
\hline Lambton & 1.00 (Ref.) & 1.00 (Ref.) \\
\hline Windsor & $0.72(0.68-0.75)$ & $0.80(0.68-0.93)$ \\
\hline London-Middlesex & $\begin{array}{l}0.64(0.59-0.69) \\
\text { (Apr. 1, 1993-Mar. 31, 2009; } \\
\quad n=114427)\end{array}$ & $0.81(0.60-1.09)$ \\
\hline \multicolumn{3}{|l|}{ Model D: $\mathrm{PM}_{2.5}$} \\
\hline Lambton & 1.00 (Ref.) & 1.00 (Ref.) \\
\hline Windsor & $0.75(0.69-0.82)$ & $0.75(0.69-0.82)$ \\
\hline London-Middlesex & $\begin{array}{c}0.71(0.63-0.81) \\
(\operatorname{Jan} 1,2003-M a r 31,2009 \\
n=44737)\end{array}$ & $0.71(0.63-0.81)$ \\
\hline \multicolumn{3}{|c|}{ Model E: all pollutants combined } \\
\hline Lambton & 1.00 (Ref.) & 1.00 (Ref.) \\
\hline Windsor & $0.79(0.62-1.01)$ & $0.79(0.62-1.01)$ \\
\hline London-Middlesex & $\begin{array}{c}0.89(0.64-1.24) \\
\text { (Jan. 1, 2003-Mar. 31, 2009; } \\
n=44737)\end{array}$ & $0.89(0.64-1.24)$ \\
\hline \multicolumn{3}{|c|}{$\begin{array}{l}\text { Note: } \mathrm{Cl}=\text { confidence interval, } \mathrm{LHIN}=\mathrm{Local} \text { Health Integration } \mathrm{Network}, \mathrm{NO}_{2}=\text { nitrogen dioxide, } \mathrm{O}_{3}=\text { ground-level ozone, } \mathrm{PM}_{2.5}= \\
\text { particulate matter } 2.5 \text { um or smaller, Ref. }=\text { reference category, } \mathrm{SO}_{2}=\text { sulphur dioxide. } \\
\text { "Adjusted for maternal age, maternal asthma, sex, rural geography, neighbourhood material deprivation, neighbourhood ethnic } \\
\text { concentration, cesarean delivery and fiscal year. The number of individuals per model is variable because the cohorts were restricted } \\
\text { to children with no missing data for exposures to pollutants. } \\
\dagger \text { Adjusted for all variables listed above, with sample size of cohorts restricted to children with available information on exposures to all } \\
\text { pollutants. }\end{array}$} \\
\hline
\end{tabular}

different pollutant levels or different marginalization characteristics) may be less important in conferring asthma risk.

We used health administrative data, so there was the potential for misclassification of our asthma outcome, despite our use of a validated algorithm. We did not use propensity scores to adjust for lifestyle factors, which may have differed between regions, and we were limited in our ability to account for some of these potential unmeasured 
contributors to asthma risk, (e.g., environmental tobacco smoke, maternal breastfeeding or exposure to allergens). In addition, many of the covariables used in our analysis could at best be attributed at the neighbourhood level, rather than the individual level.

\section{Conclusion}

We found a higher incidence of asthma among children born in the Lambton (Sarnia) LHIN subregion, relative to 2 other subregions in southwestern Ontario. We observed that $\mathrm{SO}_{2}$ and $\mathrm{PM}_{2.5}$, industrial pollutants found at highest levels in the Lambton subregion, may have contributed to this higher asthma risk. These results suggest that limiting early exposure to air pollution may be a strategy for primary prevention of asthma and could be confirmed in future studies.

\section{References}

1. Gershon AS, Guan J, Wang C, et al. Trends in asthma prevalence and incidence in Ontario, Canada, 1996-2005: a population study. Am 7 Epidemiol 2010;172:728-36.

2. Global strategy for asthma management and prevention. Fontana (WI): Global Initiative for Asthma; 2016.

3. Li X, Sundquist K, Sundquist J. Parental occupation and risk of hospitalization for asthma in children and adolescents. F Asthma 2009;46:815-21.

4. Cope SF, Ungar WJ, Glazier RH. Socioeconomic factors and asthma control in children. Pediatr Pulmonol 2008;43:745-52.

5. Chen E, Bloomberg GR, Fisher EB Jr, et al. Predictors of repeat hospitalizations in children with asthma: the role of psychosocial and socioenvironmental factors. Health Psychol 2003;22:12-8.

6. Chen Y, Stewart P, Johansen H, et al. Sex difference in hospitalization due to asthma in relation to age. 7 Clin Epidemiol 2003;56:180-7.

7. Schatz M, Cook EF, Joshua A, et al. Risk factors for asthma hospitalizations in a managed care organization: development of a clinical prediction rule. $A m \mathcal{F}$ Manag Care 2003;9:538-47.

8. Fuhrman C, Dubus JC, Marguet C, et al. Hospitalizations for asthma in children are linked to undertreatment and insufficient asthma education. 7 Asthma 2011;48:565-71.

9. Jin Y, Seiber EE, Ferketich AK. Secondhand smoke and asthma: What are the effects on healthcare utilization among children? Prev Med 2013;57:125-8.

10. Wang Z, May SM, Charoenlap S, et al. Effects of secondhand smoke exposure on asthma morbidity and health care utilization in children: a systematic review and meta-analysis. Ann Allergy Asthma Immunol 2015;115:396-401.e2.

11. Roberts G, Patel N, Levi-Schaffer F, et al. Food allergy as a risk factor for lifethreatening asthma in childhood: a case-controlled study. 7 Allergy Clin Immunol 2003;112:168-74.

12. Simpson $\mathrm{AB}$, Yousef E, Hossain J. Association between peanut allergy and asthma morbidity. 7 Pediatr 2010;156:777-81, 781.e1.

13. Brunekreef B, Holgate ST. Air pollution and health. Lancet 2002;360:1233-42.

14. Weinmayr G, Romeo E, De Sario M, et al. Short-term effects of PM10 and NO2 on respiratory health among children with asthma or asthma-like symptoms: a systematic review and meta-analysis. Environ Health Perspect 2010;118:449-57.

15. Lavigne E, Villeneuve PJ, Cakmak S. Air pollution and emergency department visits for asthma in Windsor, Canada. Can F Public Health 2012;103:4-8.

16. Burra TA, Moineddin R, Agha MM, et al. Social disadvantage, air pollution, and asthma physician visits in Toronto, Canada. Environ Res 2009;109:567-74.

17. Szyszkowicz M. Ambient air pollution and daily emergency department visits for asthma in Edmonton, Canada. Int 7 Occup Med Environ Health 2008; 21:25-30.

18. Clark NA, Demers PA, Karr CJ, et al. Effect of early life exposure to air pollution on development of childhood asthma. Environ Health Perspect 2010;118:284-90.

19. Buteau S, Doucet M, Tétreault LF, et al. A population-based birth cohort study of the association between childhood-onset asthma and exposure to industrial air pollutant emissions. Environ Int 2018;121:23-30.

20. Jerrett M, Shankardass K, Berhane K, et al. Traffic-related air pollution and asthma onset in children: a prospective cohort study with individual exposure measurement. Environ Health Perspect 2008;116:1433-8.

21. McConnell R, Islam T, Shankardass K, et al. Childhood incident asthma and traffic-related air pollution at home and school. Environ Health Perspect 2010;118:1021-6.

22. Jacquemin B, Siroux V, Sanchez M, et al. Ambient air pollution and adult asthma incidence in six European cohorts (ESCAPE). Environ Health Perspect 2015;123:613-21.
23. Cai Y, Zijlema WL, Doiron D, et al. Ambient air pollution, traffic noise and adult asthma prevalence: a BioSHaRE approach. Eur Respir 7 2017;49:1502127.

24. Martinez FD. Toward asthma prevention - Does all that really matters happen before we learn to read? N Engl f Med 2003;349:1473-5.

25. Radhakrishnan D, Shariff SZ, To T. The influence of prenatal mental health service use on the incidence of childhood asthma: a population-based cohort study. 7 Asthma 2019;56:395-403

26. Khreis H, Kelly C, Tate J, et al. Exposure to traffic-related air pollution and risk of development of childhood asthma: a systematic review and meta-analysis. Environ Int 2017;100:1-31.

27. Crighton EJ, Feng J, Gershon A, et al. A spatial analysis of asthma prevalence in Ontario. Can 7 Public Health 2012;103:e384-9.

28. MacDonald E, Rang S. Exposing Canada's Chemical Valley: an investigation of cumulative air pollution emissions in the Sarnia, Ontario area. Toronto: Ecojustice; 2007.

29. Cribb R, McIntosh E, Jarvis C, et al. In Sarnia's Chemical Valley, is 'toxic soup' making people sick? Toronto Star 2017 Oct. 14, updated 2018 Nov. 2. Available: www.thestar.com/news/world/2017/10/14/in-sarnias-chemical -valley-is-toxic-soup-making-people-sick.html (accessed 2020 Sept. 14).

30. Air pollution. Database: outdoor air pollution in cities. Geneva: World Health Organization; 2011. Available: https://www.who.int/airpollution/ data/cities-2011/en/ (accessed 2018 May 7).

31. Tackling the global clean air challenge [news release]. Geneva: World Health Organization; 2011. Available: www.who.int/mediacentre/news/releases/2011/ air_pollution_20110926/en/ (accessed 2018 May 1).

32. Oiamo TH, Luginaah IN, Atari DO, et al. Air pollution and general practitioner access and utilization: a population based study in Sarnia, 'Chemical Valley,' Ontario. Environ Health 2011;10:71.

33. Ghazawi FM, Le M, Cyr J, et al. Analysis of acute myeloid leukemia incidence and geographic distribution in Canada from 1992 to 2010 reveals disease clusters in Sarnia and other industrial US border cities in Ontario. Cancer 2019;125:1886-97.

34. Radhakrishnan DK, Dell SD, Guttman A, et al. Trends in the age of diagnosis of childhood asthma. 7 Allergy Clin Immunol 2014;134:1057-62.e5.

35. Nicholls SG, Quach P, von Elm E, et al. The reporting of studies conducted using observational routinely-collected health data (RECORD) statement: methods for arriving at consensus and developing reporting guidelines. PLoS One 2015;10:e125620.

36. Benchimol EI, Smeeth L, Guttmann A, et al.; RECORD Working Committee. The reporting of studies conducted using observational routinely-collected health data (RECORD) statement. PLoS Med 2015;12:e1001885.

37. ON-Marg: Ontario marginalization index: user guide. Version 1.0. Toronto: St. Michael's Hospital, Centre for Research on Inner City Health; 2012. Available: www.torontohealthprofiles.ca/onmarg/userguide_data/ON-Marg_user_guide_1.0_ FINAL MAY2012.pdf (accessed 2019 Sept. 16).

38. Matheson FI, Dunn JR, Smith KLW, et al. Development of the Canadian Marginalization Index: a new tool for the study of inequality. Can 7 Public Health 2012;103(Suppl 2):S12-6.

39. Air quality Ontario [main page]. Toronto: Ministry of Environment, Conservation and Parks. Available: www.airqualityontario.com/ (accessed 2019 Sept. 14).

40. National Air Pollution Surveillance Program. Ottawa: Environment and Climate Change Canada; modified 2019. Available: www.canada.ca/en/environment -climate-change/services/air-pollution/monitoring-networks-data/national-air -pollution-program.html (accessed 2020 Aug. 10).

41. Facts about Local Health Integration Network home and community care services. Toronto: Ministry of Health and Ministry of Long-Term Care; modified 2018 Nov. 16. Available: www.health.gov.on.ca/en/common/system/services/ lhin/facts.aspx (accessed 2020 Aug. 10).

42. Fung KY, Luginaah IN, Gorey KM. Impact of air pollution on hospital admissions in southwestern Ontario, Canada: generating hypotheses in sentinel high-exposure places. Environ Health 2007;6:18.

43. Haq M, Numekevor L, Singh P, et al. Community health profile: southwestern Ontario. London (ON): SouthWestern Academic Health Network; 2015, revised 2016. Available: www.swahn.ca/uploads/contentdocuments/cc license - community health profile for southwestern ontario .pdf (accessed 2020 Aug. 31).

44. Jaakkola JJ, Ahmed P, Ieromnimon A, et al. Preterm delivery and asthma: a systematic review and meta-analysis. 7 Allergy Clin Immunol 2006;118:823-30.

45. To T, Dell S, Dick PT, et al. Case verification of children with asthma in Ontario. Pediatr Allergy Immunol 2006;17:69-76.

46. Gershon AS, Wang C, Guan J, et al. Identifying patients with physician-diagnosed asthma in health administrative databases. Can Respir 7 2009;16:183-8.

47. Larsen K, Zhu J, Feldman LY, et al. The annual September peak in asthma exacerbation rates. Still a reality? Ann Am Thorac Soc 2016;13:231-9.

48. To T, Guan J, Wang C, et al. Is large birth weight associated with asthma risk in early childhood? Arch Dis Child 2012;97:169-71.

49. Kovesi T, Schuh S, Spier S, et al. Achieving control of asthma in preschoolers. CMA7 2010;182:E172-83.

50. MacDonald E. Return to Chemical Valley 2019: ten years after Ecojustice's report on one of Canada's most polluted communities. Toronto: Ecojustice; 2019. Available: https://ecojustice.ca/wp-content/uploads/2019/06/Return-to-Chemical-Valley_ FINAL.pdf (accessed 2020 Nov. 4).

51. Garcia E, Berhane KT, Islam T, et al. Association of changes in air quality with incident asthma in children in California, 1993-2014. FAMA 2019;321:1906-15. 
52. Pennington AF, Strickland MJ, Klein M, et al. Exposure to mobile source air pollution in early-life and childhood asthma incidence: the Kaiser Air Pollution and Pediatric Asthma Study. Epidemiology 2018;29:22-30.

53. Salam MT, Islam T, Gilliland FD. Recent evidence for adverse effects of residential proximity to traffic sources on asthma. Curr Opin Pulm Med 2008;14:3-8.

54. Bråbäck L, Forsberg B. Does traffic exhaust contribute to the development of asthma and allergic sensitization in children: findings from recent cohort studies. Environ Health 2009;8:17.

55. Achakulwisut P, Brauer M, Hystad P, et al. Global, national, and urban burdens of paediatric asthma incidence attributable to ambient $\mathrm{NO}_{2}$ pollution: estimates from global datasets. Lancet Planet Health 2019;3:e166-78.

56. Bowatte G, Lodge C, Lowe AJ, et al. The influence of childhood traffic-related air pollution exposure on asthma, allergy and sensitization: a systematic review and a meta-analysis of birth cohort studies. Allergy 2015;70:245-56.

57. Kravitz-Wirtz N, Teixeira S, Hajat A, et al. Early-life air pollution exposure, neighborhood poverty, and childhood asthma in the United States, 1990-2014. Int 7 Environ Res Public Health 2018;15:1114.

58. Anderson HR, Favarato G, Atkinson RW. Long-term exposure to air pollution and the incidence of asthma: meta-analysis of cohort studies. Air Qual Atmos Health 2013;6:47-56.

59. Young MT, Sandler D, DeRoo LA, et al. Ambient air pollution exposure and incident asthma in a nationwide cohort of U.S. women. Am 7 Respir Crit Care Med 2014;190: 914-21.

60. Thurston GD, Balmes JR, Garcia E, et al. Outdoor air pollution and newonset airway disease. An official American Thoracic Society workshop report. Ann Am Thorac Soc 2020;17:387-98.

61. Jung CR, Chen WT, Tang YH, et al. Fine particulate matter exposure during pregnancy and infancy and incident asthma. I Allergy Clin Immunol 2019;143:2254-62.e5.

62. Ji H, Biagini Myers JM, Brandt EB, et al. Air pollution, epigenetics, and asthma. Allergy Asthma Clin Immunol 2016;12:51.

63. Guarnieri M, Balmes JR. Outdoor air pollution and asthma. Lancet 2014:383:1581-92.

64. Turner SW, Young S, Goldblatt J, et al. Childhood asthma and increased airway responsiveness: a relationship that begins in infancy. Am 7 Respir Crit Care Med 2009;179:98-104.

65. Hofhuis W, de Jongste JC, Merkus PJFM. Adverse health effects of prenatal and postnatal tobacco smoke exposure on children. Arch Dis Child 2003; 88:1086-90.

66. Stiemsma LT, Turvey S. Asthma and the microbiome: defining the critical window in early life. Allergy Asthma Clin Immunol 2017;13:3.

67. McKeever TM, Lewis SA, Smith C, et al. The importance of prenatal exposures on the development of allergic disease: a birth cohort study using the West Midlands General Practice Database. Am 7 Respir Crit Care Med 2002;166:827-32.

Affiliations: Children's Hospital of Eastern Ontario Research Institute (Radhakrishnan); Department of Pediatrics (Radhakrishnan), University of Ottawa; ICES uOttawa (Radhakrishnan), Ottawa, Ont.; ICES Western (Bota, Ouédraogo, Clemens, Shariff); London Health Sciences Centre (Price, Husein); Departments of Pediatrics (Price), of Surgery (Husein), of Medicine (Clemens), and of Epidemiology and Biostatistics (Clemens), Western University; Lawson Health Research Institute (Price, Husein, Shariff), London, Ont.
Contributors: All of the authors participated in study design. Alexandra Ouédraogo and Salimah Shariff performed the data analysis, and all of the authors participated in interpreting the results. Dhenuka Radhakrishnan wrote the first draft of the manuscript, and all of the authors revised the manuscript for important intellectual content. All of the authors approved the final version to be published and agreed to be accountable for the work.

Funding: This study was supported by ICES, which is funded by an annual grant from the Ontario Ministry of Health and the Ontario Ministry of Long-Term Care. The study was completed at the ICES Western site, where core funding is provided by the Academic Medical Organization of Southwestern Ontario, the Schulich School of Medicine and Dentistry, Western University and the Lawson Health Research Institute (LHRI). This study also received funding from an LHRI Internal Research Fund grant.

Disclaimer: This study was supported by ICES, which is funded by an annual grant from the Ontario Ministry of Health and the Ontario Ministry of Long-Term Care. Parts of this material are based on data and information compiled and provided by the Canadian Institute for Health Information, the Ontario Ministry of Health and Long-Term Care (now 2 separate ministries) and the Ontario Ministry of the Environment. The results, analyses, conclusions, opinions and statements expressed herein are solely those of the authors and are independent from the funding and data sources. No endorsement by ICES, the Ontario Ministry of Health, the Ontario Ministry of Long-Term Care or the Ontario Ministry of the Environment is intended or should be inferred.

Content licence: This is an Open Access article distributed in accordance with the terms of the Creative Commons Attribution (CC BY-NC-ND 4.0) licence, which permits use, distribution and reproduction in any medium, provided that the original publication is properly cited, the use is noncommercial (i.e., research or educational use), and no modifications or adaptations are made. See: https://creativecommons.org/licenses/ by-nc-nd/4.0/

Data sharing: The data set from this study are held securely in coded form at ICES. Although legal data-sharing agreements between ICES and data providers (e.g., health care organizations and government) prohibit ICES from making the data set publicly available, access may be granted to those who meet prespecified criteria for confidential access, available at https://www.ices.on.ca/DAS (email: das@ices.on.ca). The full data set creation plan and underlying analytic code are available from the authors upon request, with the understanding that the computer programs may rely upon coding templates or macros that are unique to ICES and are therefore either inaccessible or may require modification.

Supplemental information: For reviewer comments and the original submission of this manuscript, please see www.cmajopen.ca/content/9/2/ E433/suppl/DC1. 